\title{
Self-perceived creativity and ambiguous figure reversal rates
}

\author{
JUDITH E. BERGUM and BRUCE O. BERGUM \\ Texas A\&M University, College Station, Texas 77840
}

\begin{abstract}
Earlier research suggested a relationship between career orientation and perceptual stability. The present study was conducted to test the hypothesis that, regardless of specific academic discipline, individuals demonstrating relatively high rates of reversals to ambiguous geometric figures would perceive themselves as more creative, or more original, than individuals demonstrating low rates of reversals. Two groups of 30 subjects each, selected from 128 undergraduates on the basis of their demonstrated reversal rates, were tested in terms of their self-perceptions. As predicted, the high-reversal group saw itself as more creative and original, and as generally more responsive and optimistic than the low-reversal group.
\end{abstract}

Earlier studies indicated that individuals of demonstrated creative ability, as measured by patents and publications, see themselves as uniquely different from and more creative than other persons in general (Bergum, 1974, 1975). In addition, a more recent experiment demonstrated that individuals, such as architects, who by tradition are thought to be visually creative, see themselves as generally more creative than do people who are not typically engaged in visually creative activities and display predictably significant higher levels of perceptual instability, as well (Bergum \& Bergum, 1979). The comparison groups in this study were undergraduate architecture and business majors.

While the results of the latter study supported the hypothesis that visually creative individuals would display higher perceptual instability, it did not answer the obverse question of whether the phenomenon is confined to visually creative people alone, or whether in fact perceptual instability might be associated with self-perceived creativity in general, regardless of any professional orientation. Thus, the hypothesis for the present study was that individuals who display high levels of perceptual instability, as measured by ambiguous figure reversal rates, would perceive themselves as more creative and original than individuals showing high levels of perceptual stability. To test this hypothesis, a random sample of undergraduate students was tested in terms of figure reversal rates and two measures of self-perception.

\section{METHOD}

\section{Subjects}

A total of 128 undergraduate students from all the major schools on campus served as the subjects in this study. There were 59 females and 69 males.

\section{Materials}

A Sawyers Model 500 35-mm slide projector was the primary apparatus employed. Additional materials included six-page response booklets (Bergum \& Bergum, 1979) and individual slides depicting six common ambiguous figures including the Necker cube, Mach figure, Rubin face-vase, truncated pyramid, accordian fold figure, and Jastrow rabbit-duck figure (Attneave, 1971). A small red fixation dot was centered on each illustration.

The self-perception test materials included a 20 -item biographical inventory (Bergum, 1975) and a 33-item adjective checklist (Gough, 1961).

\section{Procedure}

Subjects responded first to the self-perception forms; then they were instructed in the nature of the reversal experience in which they were shown two ambiguous figures other than those used in the experiment proper. They were instructed to fixate on the red dot each time a figure was presented and to mark their booklets on the appropriate page each time they experienced a reversal without looking away from the figure. The test figures were shown for $60 \mathrm{sec}$ each in random sequence in both forward and reversed orders to control for potential sequential and positional effects and for basic differences in the potential reversibility of the figures.

The data were collected in three separate sessions in the same room, employing random groups of approximately the same size $(N=40)$ on each occasion.

\section{RESULTS AND DISCUSSION}

Based upon the total number of reversals for each subject, the data were separated first into two groups of 30 subjects each, regardless of school or group affiliation and in contrast to the earlier study. The mean number of reversals across all figures for the top 30 reversers was 523, and for the lowest 30 reversers was 395 , a $34 \%$ difference. There were 15 females and 15 males in the high-reversal (HR) group, and 13 females and 17 males in the low-reversal (LR) group. These groups were then compared on the basis of their responses to the self-perception measures.

In terms of the biographical inventory, the HR group saw itself as both more creative $\left(\chi_{1}^{2}=5.46, p<.05\right)$ and more original $\left(\chi_{1}^{2}=5.46, p<.05\right)$ than did the $L R$ group.

The adjective checklist data yielded several items that 
tended to discriminate between the groups. At the $1 \%$ level of significance, the HR group saw itself as more enthusiastic $\left(\chi_{1}^{2}=15.02\right)$, more logical $\left(\chi_{1}^{2}=7.14\right)$, and more optimistic $\left(\chi_{1}^{2}=7.17\right)$ than did the LR group, while at the $5 \%$ level of significance, the HR group saw itself as more rational $\left(\chi_{1}^{2}=4.28\right)$, more original $\left(\chi_{1}^{2}=4.29\right)$, more idealistic $\left(\chi_{1}^{2}=4.00\right)$, more excitable $\left(\chi_{1}^{2}=5.41\right)$, and more appreciative $\left(\chi_{1}^{2}=5.97\right)$ than did the LR group. These results are similar to those found in the earlier studies in which creative individuals tended to see themselves as more naive, or idealistic, than otherwise comparable people. Generally, the results for the combined measures suggest that self-perceived creatives and individuals displaying high perceptual instability, who are frequently the same persons, tend to be more responsive, empathic, and optimistic than the larger population.

In general, the combined results from the earlier and the present studies support the statement that individuals who see themselves as more creative in fact do also display greater perceptual instability than those who do not perceive themselves as particularly creative, and conversely, that individuals who show high levels of perceptual instability also see themselves as more creative and original than low-rate-of-reversal individuals. Thus, perceptual stability and self-perceived creativity appear to be significantly related from whichever point the phenomena are viewed.

\section{REFERENCES}

Attneave, F. Multistability in perception. Scientific American, 1971, 225(6), 62-71.

BERGUM, B. O. Self-perceptions of members of a graduate faculty whose publication rates are high or low. Psychological Reports, 1974, 35, 857-858.

Bergum, B. O. Self-perceptions of creativity among academic inventors and non-inventors. Perceptual and Motor Skills, 1975, 40, 78

Bergum, B. O., \& Bergum, J. E. Creativity, perceptual stability, and self-perception. Bulletin of the Psychonomic Society, 1979, 14, 61-63.

Gough, H. G. Techniques for identifying the creative research scientist. In D. W. MacKinnon (Ed.), The creative person. Berkeley: University of California Extension, 1961.

(Received for publication July 25, 1979.) 